\title{
Review
}

\section{The common cold}

\author{
G.B.Stickler ${ }^{1}$, T.F.Smith ${ }^{2}$, and D.D. Broughton ${ }^{1}$ \\ ${ }^{1}$ Department of Pediatrics and ${ }^{2}$ Section of Clinical Microbiology, Mayo Clinic and Mayo Foundation, Rochester, Minnesota, USA
}

\begin{abstract}
The common cold continues to be the major cause of absences from school and work. A better understanding of the epidemiology and the natural history should lead to less anxiety about this disease. Although there is still much misinformation among the public, the time should soon come when better-informed patients with this disease will make fewer visits to the physician and will not expect unnecessary and worthless treatment.
\end{abstract}

Key words: Common cold - Rhinovirus - Coronavirus - Treatment with fixed-dose combinations - Treatment with expectorants

\section{Introduction}

The "common cold" can be defined as a viral infection causing inflammation of the mucous membranes of the upper respiratory tract, i.e., nose, pharynx, and trachea. The symptoms include rhinorrhea, soreness of throat, sometimes hoarseness, and initially an irritant cough which later becomes loose. There is general malaise, but usually not any fever, at least in the older child and adult.

Some authors use the term "upper respiratory-tract infection" (or "URI") for the same symptom complex. Other synonyms include "cold", "head cold", and "chest cold." In daily conversation it is clear that everybody understands what is meant by having a "cold" or a "Schnupfen, Erkältung" in German, "rhume" in French, or "raffredore" in Italian.

As virology was burgeoning in the 1950 s and 1960 s, much was learned about the identification and transmission of viruses that cause the common cold. However, few significant advances have been made toward prevention or definitive treatment; and in recent years interest has been low $[14,35]$. Major pediatric textbooks devote no more than one-half to two pages to this illness, and formal teaching about the common cold is seldom offered in medical schools or continuing medical education courses. Among the public, victims of this illness are more often guided by television advertising and word-of-mouth lore than informed of sound medical principles.

Offprint requests to: Dr. Gunnar B. Stickler, Department of Pediatrics, Mayo Clinic, Rocheser, MN 55905, USA
The low level of professional interest is probably related to the fact that the common cold is a self-limited illness and only infrequently leads to serious complications. Despite the benign course, $95 \%$ of a group of physicians who participated in a prospective study of prescribing habits gave one or more prescription drugs to patients with the common cold, and $60 \%$ of these prescriptions were for antibiotics [39].

There is an underlying belief that the common cold is insignificant, although the individual cold sufferer may not concur. Actually, in addition to the specific discomfort, the common cold has an important impact on a very wide scale. Shah and associates [37] estimated that there were 23-42 million episodes of upper respiratory infections througout Canada in a single year. Five million of these patients were seen by a physician, and 215,000 were admitted to a hospital for a total of 742,800 hospital days. The estimated cost in 1973 was 143-211 million Canadian dollars. Extrapolation to the United States at 1984 prices would bring the sum to nearly 5 billion dollars per year. Gwaltney [14] estimated that 55 million school and work days were lost for the same reason in 1969. In a separate study, he and his associates found that self-diagnosed respiratory illnesses resulted in $36 \%$ of a manufacturing company's total absenteeism [16].

\section{Etiology, epidemiology, and transmission}

The first human infectivity studies of the common cold were done at the end of the 19th century. In 1914 Walther Kruse [25] of Leipzig found that the causative agents passed through bacterial filters and thus presumably were virus-like. In 1933 Paul and Freese [29], after studying an isolated community in Spitzbergen, concluded that the common cold is "initiated by one or more specific, infective agents and that the disease is spread by direct contact. The incubation period appeared to be about $48 \mathrm{~h}$." They further showed that the frequency of illness was not affected significantly by the bacterial flora of the nasopharynx or by the climate, but was related to the arrival of supply ships. A study done later on Tristan da Cunha, a South Atlantic island with a population of 200 people, gave similar results [43].

In the $1950 \mathrm{~s}$, many viruses were found to be associated with common cold symptoms [4, 30, 34]. Among them, rhinovirus alone has more than 100 different serotypes. In her most recent review, Reed [35] estimated that $50 \%$ of common colds 
are due to rhinovirus (which is the subject of many studies), $15 \%-20 \%$ to coronavirus, $15 \%-20 \%$ to parainfluenza virus and respiratory syncytial virus, and the remainder to enterovirus, influenzavirus, and others. One study found that $30 \%-$ $40 \%$ of infected persons have lower respiratory-tract symptoms [17].

Much of the knowledge about the epidemiology of viral infections has come from work with adult volunteers, but there is no reason to doubt that this information applies to children as well.

Estimates of the incidence of infection with rhinovirus and with coronavirus vary because of difficulties in isolating these viruses from patients. Seattle infants, studied prospectively during their 1st year of life, typically had six to eight colds; but definite isolation or serologic identification or rhinovirus was accomplished only 0.8 times per patient-year [11]. Gardner and colleagues [12], studying viral infections in infants from birth to first birthday, attributed $18 \%$ to rhinoviruses and the rest to respiratory syncytial virus, parainfluenza 1, 2, and 3, adenovirus, influenza $\mathrm{A}$ and $\mathrm{B}$, and picornaviruses. Hable and co-workers [19] at our institution, by pharyngeal culture alone, were able to isolate rhinovirus from just 6 of 490 children who had a variety of upper respiratory-tract infections. In addition to the difficulty of isolating the virus, differences of protocol may cause disagreements between study results. Patients at the Mayo Clinic actively sought medical care, perhaps because of the severity of symptoms, whereas in other epidemiologic studies the investigators took the initiative.

In common colds due to any of numerous viruses, age affects both the frequency of infection and the duration of the symptoms. Shah and associates [37] estimated that preschool children (up to age 4 years) have a frequency of 5.4-8.1 colds per year, whereas in the age group 10-14 years it drops to 2.75.5 per year. The preschool child is symptomatic $20 \%$ of the time or almost 2.5 months of each year, and the child in school suffers from these symptoms a cumulative total of 1 month of the year. Longini and associates [26] found the attack rates with rhinovirus were highest in subjects $0-4$ years old and declined gradually to age 65 and older. This report agrees with the observation that newborns have antibodies to about $20 \%$ of rhinoviruses. The number falls sharply during the 1 st year of life and then gradually rises again [15]. There is no convincing evidence that breast feeding protects against the common cold, nor is the presence of atopic diathesis clearly associated with an increased number of infections. Parental smoking, at least in one study, had no effect on the frequency of infection of infants [12]. Presence of preschool siblings increased the infection rate, but the presence of a school-age sibling did not. In the same study, no effect of socioeconomic class on the rate of infection in infants was noted [12].

Seasonal variation also exists: in this country, (USA) peaks occur in September and October and again in early spring [11]. It is not known whether the first peak is due to the reopening of school or to other factors. In the tropics the disease is most common during the rainy season [40].

Gwaltney and associates [16] found that during a common cold the isolation rate of virus from patients did not change during a 5-day period, and they concluded that the disease is infectious for about 3-5 days. However, rhinovirus excretion lasting as long as 7-10 days has been noted [35]. Infectivity seems also to be related to the amount of virus shed. The virus is most easily transmitted from one person to another by manual contact (for example, nose to hand to table to hand to nose). Hand washing is an important factor in preventing the spread of infection. Airborne spread occurs also, via largeparticles such as droplets from sneezing or coughing, but much less often [18].

Not surprisingly, infections occur more often as the total time of exposure increases. Among married couples, the frequency of infection of serologically susceptible partners was proportional to the number of hours spent in the same room together, but not necessarily to the time spent in physical contact [7]. Interestingly, there is little transmission of the virus through kissing because the mucous membranes of the oral cavity have a relatively high resistance to the virus [7].

Exposure to a cold or wet environment does not increase the chance of becoming infected with a common cold [9]. On the other hand, physical or emotional stress may be associated with higher susceptibility. Smokers also may be more susceptible than nonsmokers [41]. There are no data about the effects of various industrial pollutants. Children have a higher incidence of colds just before and after tonsillectomy and adenoidectomy [8].

Resistance to rhinovirus infections may be due simply to the presence of protecting antibody (which is serotype-specific), and susceptibility may be due to lack of such immunity to whichever serotype is encountered, from the hundred or more that are existent. Immediate recovery from infection, however, seems to depend on factors other than measurable serum or nasal antibodies [22]. Turner and co-workers [42] suggested that the symptoms of rhinovirus infections could be triggered by infection of the nasal epithelium and may include the activation of chemical mediators of inflammation such as histamine, prostaglandins, and kinins. These substances may cause increase of vascular permeability, subsequent edema, and resulting transudation of serum, thus contributing to nasal obstruction and rhinorrhea.

\section{Clinical features}

\section{Symptoms and signs}

The common cold is a self-limited disease manifested primarily as inflammation of the mucous membranes of the respiratory tract, beginning $2-4$ days after inoculation with the infecting virus. It rarely has serious consequences. The initial symptom usually is soreness or scratchiness of the throat; sneezing follows, and then rhinorrhea. Secretions are clear initially, but become purulent within a few days and can cause nasal obstruction. Children may have fever, but it is not usually so prominent in colds as it can be in other viral syndromes. General malaise and muscle aches and pains are often a major complaint of the older child and adult.

Not uncommonly, patients have a hoarse voice, burning or pain in the retrosternal region, and irritative cough. These symptoms are most severe on the 3rd and 4th days of the illness. The cough changes from irritative and dry to loose, "deep," and sometimes slightly productive. Ear symptoms such as pain or a plugged sensation are not uncommon, especially in children.

On physical examination, inflamed and swollen mucous membranes in the nasopharynx and clear to purulent secretions in the nose are seen. The tympanic membranes may be slightly red, and there may be some fluid in the middle ear, but bulging or other signs of overt infection should not be 
present. The conjunctiva may be reddened and inflamed. The cervical lymph nodes often are enlarged. Auscultation of the chest usually gives negative results; but a faint expiratory wheeze may be heard, especially in smaller children.

\section{Clinical course}

In discussing the illness with the patient or the parents, it is crucial that they understand the natural course of the disease. Particularly, they should not be left with inappropriate expectations as to the duration of the illness or the effect of therapy.

In adults, most symptoms disappear after 1 week, but $20 \%$ have symptoms for 2 weeks or more. Of children, $35 \%$ are symptomatic for at least 2 weeks [28]. Cough lasting longer than 1 week in a child with a common cold should not be regarded as an alarm signalling pneumonia, and it is not an indication for chest roentgenography in the absence of appropriate physical findings. Although there is a popular belief that a cold may "settle in the lung" or cause pneumonia, there is little clinical or radiologic evidence to support such a view.

Viral infections, including those with the rhinovirus and coronavirus, can cause exacerbations of chronic bronchitis in adults [13]; and spirometric studies in children have shown that the common cold may reduce forced expiratory flow rates [5]. There is bronchial epithelial damage, which may cause exaggerated bronchial muscle reactivity and probably a vagally mediated reflex resulting in generalized bronchospasm [20].

The relationship of rhinovirus infection to "wheezy bronchitis" in children was studied by Horn and co-workers [23]. In their definition, "wheezy bronchitis" is an acute illness usually preceded by rhinorrhea, and it is characterized by cough and variable degrees of wheezing, breathlessness, and mucous expectoration. Synonyms used in this country are "asthmatic bronchitis" and "infectious asthma." These authors were able to isolate the rhinovirus in $49 \%$ of all episodes and in $64 \%$ of severe episodes that required treatment with steroids. Clearly, only a small group of infants and children have the asthmatic type of bronchitis in the course of a common cold infection; but, in this group it tends to recur with each new infection.

\section{Management}

There is no cure for the common cold. Aside from a few simple measures for general well-being, treatment only relieves some of its symptoms.

\section{Popular recommendations}

Advertising campaigns have suggested that the best therapy for a cold consists in rest, fluids, and acetylsalicylic acid. This very widespread advice has influenced medical practice, and its components should be given objective attention.

First, salicylates and acetaminophens have no predestined place in treatment of a cold. They are indicated only if there is fever or significant pain.

Second, there is no clear evidence that increased fluid intake is helpful. Exhortations to drink plenty of fluids probably result in nothing more than polyuria.

Finally, there is no objective evidence that rest shortens the course of illness.

\section{Medical advice}

For general well-being. Although rest may be desirable, restriction of activity is generally difficult to impose. Fortunately, younger children often will set their own pace appropriately when ill. Older children and adults, on the other hand, may need to be advised to slow down and restrict activities when they are not feeling well. It is not necessary to stay indoors. Indeed, many patients with colds feel better spending some time out of doors.

There is no good reason why a child with a cold should not go to school unless the symptoms are quite severe, since exposure of classmates may have occurred before the patient became symptomatic.

In a controlled study, hot liquids increased nasal mucous velocity more than cold liquids did-and the old remedy of chicken soup appeared to be even more effective than hot water [36]. The clinical significance of that study is not clear. Certainly there is no indication to force liquids.

For nasal symptoms. Nasal obstruction can cause considerable discomfort in the cold sufferer and may be more of a problem in the younger infant, in whom nose breathing is more important.

Increased humidity in the inspired air is important in giving symptomatic relief, particularly in winter. Cold-mist vaporizors or humidifiers can be used. Hot vaporizors have been associated with scalding burns in children. There is no reason to add any medication to the water in the vaporizor.

To loosen nasal secretions, saline nose drops are recommended. They are available commercially but can be prepared easily at home by adding one-quarter of a teaspoon of salt to 1 cup of water. Placement of a few drops in each nostril is followed by nasal suction or, in the older child, by nose blowing. This simple remedy works well in adults also, but many adults are unwilling to use it.

To relieve edema, topical vasoconstrictors such as phenylephrine are effective; but they should be used with caution because of the rebound phenomenon and potential for overuse. The value of systemic vasoconstrictors has not been critically evaluated. There is no reason that the nose should be more sensitive to their action than other areas of the body [44]. Also, there are many contraindications to the use of these compounds.

To promote dryness, antihistamines are useful [24, 27]. This effect is most likely due to their atropine-like action rather than to any antihistaminic action [7]. They also often function as mild sedatives. Their usefulness in management of the common cold is unsubstantiated, however: they do not shorten the course of the illness nor prevent any subsequent complications.

Neither decongestants nor antihistamines have been shown to be effective in preventing otitis media in children.

For cough. In many cases cough is a troublesome symptom, and in some the most troublesome of all.

It is useful for patients to understand why the cough is present, and to know it may be helpful in clearing secretions. Most coughing will be relieved or improved by the measures already discussed.

In safe dosage, expectorants have never been proven to ease coughing. Cough suppressants do have some preventive power; but as suggested, there may be times when suppression 
of the cough is disadvantageous. Combinations of expectorants and cough suppressants make no scientific sense [2].

Not appropriate. Physicians should acknowledge that antibiotics are of no use in treatment of the common cold. Nor is there evidence that antibiotics prevent bacterial complications in patients who are healthy except for colds. Unless their administration is indicated for other reasons, such as prophylaxis of rheumatic fever, recurrence of ear infections, or presence of bacterial infections, they should not be used.

A great deal has been written about the value of vitamin $C$. It has never been shown convincingly that this vitamin prevents or alters the course of the common cold. The effects that have shown in some studies are negligible $[2,3,6,10,33,38]$.

Logically, vaccination offers no realistic prospect for the control of rhinovirus infection, because the serotypes of the virus are so numerous. Further, no common antigen of the infective virus has been recognized which might be neutralized by an appropriate antibody [31].

In addition to the various regimens aimed at specific symptoms, countless fixed-dose combinations are available either by prescription or over the counter. There is no indication that the ingredients are more effective together than individually. Further, if the dosage chosen is appropriate for one ingredient, there is likely to be too much or too little of the others for the particular case. The physician should not resort to such preparations.

\section{Conclusion}

Thus far no method has been found to avoid the common cold, unless by moving into complete isolation in the Arctic. For the future, one possibility may be the use of antiviral drugs with known efficacy against rhinoviruses. For example, nasal administration of antiviral drugs such as enviroxime or interferon $\alpha 2$ (IFN- $\alpha 2$, which was produced by recombinant DNA techniques), in experimentally induced rhinovirus infection, was found to reduce the level and duration of viral shedding and of nasal mucus production [21, 31, 32].

At present, it is important that we teach our patients that we can relieve significant symptoms but that drugs should not be used indiscriminately whenever there is slight discomfort. It is best to treat specific symptoms that are causing significant problems and to reassure the patient by teaching him or her what to expect during the course of the illness. Actually, patients eventually stop using any medication for colds; and in most instances they are not ill-served by this decision.

\section{References}

1. AMA Department of Drugs (1980) Cold remedies. In: AMA Drug Evaluations, 4th edn. American Medical Association, Chicago, pp 461-466

2. AMA Department of Drugs (1980) Agents used to treat cough. In: AMA Drug Evaluations, 4th edn. American Medical Association, Chicago, pp 467-475

3. Anderson TW (1979) Vitamin C: Cure for the common cold? Am Pharm 19:46-48

4. Andrewes CH, Chaproniere DM, Gompels AEH, Pereira HG, Roden AT (1953) Propagation of common-cold virus in tissue cultures. Lancet II :546-547

5. Collier AM, Pimmel RL, Hasselblad V, Clyde WA Jr, Knelson JH, Brooks JG (1978) Spirometric changes in normal children with upper respiratory infections. Am Rev Respir Dis 117:47-53
6. Coulehan JL (1979) Ascorbic acid and the common cold: Reviewing the evidence. Postgrad Med 66:153-160

7. D'Alessio DJ, Peterson JA, Dick CR, Dick EC (1976) Transmission of experimental rhinovirus colds in volunteer married couples. J Infect Dis 133:28-36

8. Dingle JH (1966) The common cold and common cold-like illnesses. Med Times $94: 186-195$

9. Douglas RG Jr, Lindgren KM, Couch RB (1968) Exposure to cold environment and rhinovirus common cold: Failure demonstrate effect. N Engl J Med 279:742-747

10. Elwood PC, Hughes SJ, Leger AS (1977) A randomized controlled trial of the therapeutic effect of vitamin $\mathrm{C}$ in the common cold. Practitioner 218: 133-137

11. Fox JP, Cooney MK, Hall EE (1975) The Seattle virus watch. V. Epidemiologic observations of rhinovirus infections, 1965-1969, in families with young children. Am J Epidemiol 101:122-143

12. Gardner G, Frank AL, Taber LH (1984) Effects of social and family factors on viral respiratory infection and illness in the first year of life. J Epidemiol Community Health 38:42-48

13. Gump DW, Phillips CA, Forsyth BR, McIntosh K, Lamborn KR, Stouch WH (1976) Role of infection in chronic bronchitis. Am Rev Respir Dis 113: 465-474

14. Gwaltney JM Jr (1969) The common cold: Progress and perspectives. Hosp Pract 4:84-93

15. Gwaltney JM Jr (1983) Rhinovirus colds: Epidemiology, clinical characteristics and transmission. Eur J Respir Dis [Suppl] 128: 336-339

16. Gwaltney JM Jr, Hendley JO, Simon G, Jordan WS Jr (1966) Rhinovirus infections in an industrial population. I. The occurrence of illness. N Engl J Med 275:1261-1268

17. Gwaltney JM Jr, Hendley JO, Simon G, Jordan WS Jr (1967) Rhinovirus infections in an industrial population. II. Characteristics of illness and antibody response. JAMA 202:494-500

18. Gwaltney JM Jr, Moskalski PB, Hendley JO (1978) Hand-to-hand transmission of rhinovirus colds. Ann Intern Med 88:463-467

19. Hable KA, Washington JA II, Herrmann EC Jr (1971) Bacterial and viral throat flora: Comparison of findings in children with acute and upper respiratory tract disease and in healthy controls during winter. Clin Pediatr 10:199-203

20. Hall WJ, Douglas RG Jr (1980) Pulmonary function during and after common respiratory infections. Annu Rev Med 31:233-238

21. Hayden FG, Gwaltney JM Jr (1983) Intranasal interferon $\alpha 2$ for prevention of rhinovirus infection and illness. J Infect Dis 148: $543-550$

22. Hendley JO (1983) Rhinovirus colds: Immunology and pathogenesis. Eur J Respir Dis [Suppl] 128:340-343

23. Horn MEC, Reed SE, Taylor P (1979) Role of viruses and bacteria in acute wheezy bronchitis in childhood: A study of sputum. Arch Dis Child 54:587-592

24. Howard JC Jr, Kantner TR, Lilienfield LS, Princiotto JV, Krum RE, Crutcher JE, Belman MA, Danzig MR (1979) Effectiveness of antihistamines in the symptomatic management of the common cold. JAMA 242:2414-2417

25. Kruse W: Cited by Gwaltney JM Jr [14]

26. Longini IM Jr, Monto AS, Koopman JS (1984) Statistical procedures for estimating the community probability of illness in family studies: Rhinovirus and influenza. Int J Epidemiol 13:99-106

27. McGuinness BW (1976) Trial of a long-acting antihistamine in the treatment of coryza. Br J Clin Pract 30:15-16

28. Parrott RH (1979) Rhinoviral infections. In: Vaughan VC III, McKay RJ Jr, Behrman RE (eds) Nelson Textbook of Pediatrics, 11th edn. WB Saunders Company, Philadelphia, pp 905-906

29. Paul JH, Freese HL (1933) An epidemiological and bacteriological study of the "common cold" in an isolated arctic community (Spitzbergen). Am J Hyg 17:517-535

30. Pelon W, Magabgab WJ, Phillips IA, Pierce WE (1957) A cytopathogenic agent isolated from naval recruits with mild respiratory illnesses. Proc Soc Exp Biol Med 94 : 262-267

31. Phillpotts RJ, Jones RW, DeLong DC, Reed SE, Wallace J, Tyrrell DAJ (1981) The activity of enviroxime against rhinovirus infection in man. Lancet $\mathrm{I}: 1342-1344$ 
32. Phillpotts RJ, Wallace J, Tyrrell DAJ, Tagart VB (1983) Therapeutic activity of enviroxime against rhinovirus infection in volunteers. Antimicrob Agents Chemother 23:671-675

33. Pitt HA, Costrini AM (1979) Vitamin C prophylaxis in Marine recruits. JAMA 241: 908-911

34. Price WH (1956) The isolation of a new virus associated with respiratory clinical disease in humans. Proc Natl Acad Sci USA $42: 892-896$

35. Reed SE (1981) The aetiology and epidemiology of common colds, and the possibilities of prevention. Clin Otolaryngol 6:379 387

36. Saketkhoo K, Januszkiewicz A, Sackner MA (1978) Effects of drinking hot water, cold water, and chicken soup on nasal mucus velocity and nasal airflow resistance. Chest 74:408-410

37. Shah CP, Chipman ML, Pizzarello LD (1976) The cost of upper respiratory tract infections in Canadian children. $\mathrm{J}$ Otolaryngol $5: 505-512$

38. Stickler GB (1980) Polypharmacy and poisons in pediatrics: The epidemic of overprescribing and ways to control it. Adv Pediatr $27: 1-29$
39. Stolley PD, Lasagna L (1969) Prescribing patterns of physicians. J Chronic Dis 22:395-405

40. Sutton RNP (1965) Minor illness in Trinidad: A longitudinal study. Trans R Soc Trop Med Hyg 59:212-220

41. Totman R, Reed SE, Craig JW (1977) Congenitive dissonance, stress and virus-induced common colds. J Psychosom Res 21:5563

42. Turner RB, Hendley JO, Gwaltney JM Jr (1982) Shedding of infected ciliated epithelial cells in rhinovirus colds. J Infect Dis $145: 849-853$

43. Tyrrell DAJ (1977) Aspects of infection in isolated communities. Ciba Found Symp 49:137-143

44. Weiner N (1980) Norepinephrine, epinephrine, and the sympathomimetic amines. In: Gilman AG, Goodman LS, Gilman A (eds) Goodman and Gilman's the Pharmacological Basis of Therapeutics, 6th edn. Macmillan Publishing Company, New York, pp 138-175

Received June 6, 1984 / Accepted October 17, 1984 